the obscurity attaching to the subject of Abyssinian ethno$\log \mathrm{y}:-$

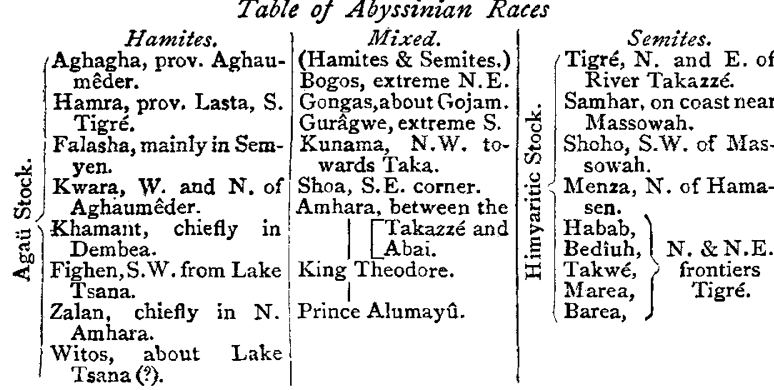

Of the languages three only are of any literary or political interest: Ghêz, still surviving as the language of the liturgy and Sacred writings, though scarcely understood even by the clergy; Tigrái, its purest modern representative, current throughout the kingdom of Tigre and generally north and east of the Takazze; Amharna, spoken with considerable dialectic variety in Amhara and Shoa. All are written in a peculiar syllabic character showing certain affinities to the Himyaritic rock inscriptions of Marah and other parts of South Arabia. Amharic employs seren additional letters for sounds not occurring in Ghêz or Tigrâi, making with the vocal modifications a total of 249 distinct symbols. This was the language of Prince Alumayû.

A. H. KEANE

COLOUR-VISION AND COLOUR-BLINDNESS

$A S$ the notices of these subjects which have recently A appeared in NATURE appear to me to do scant justice to the received theory, will you permit me to call attention to a portion of the evidence on which this theory rests?

The Philosophical Transactions for 1860 contain a paper by Prof. Clerk Maxwell, in which actual measurements are given of the quantitative relations between various colours, some of the observations having been taken by persons of normal vision, and others by a colourblind person. The instrument of observation consisted of a species of spectroscope with three parallel slits, the widths of these slits, and also the distances between them being variable at pleasure. By this means three overlapping spectra are obtained, and any three spectral colours can be mixed in any proportions. The observations showed that any four colours as presented to the eye in a given spectrum are connected with each other by a definite colour-equation, such as-

$$
3 A+4 B=2 C+6 D \text {, }
$$

which means that if the four colours $A, B, C, D$, as they exist in the given spectrum, are increased in intensity threefold, fourfold, twofold, and sixfold respectively, and then mixed two and two, the mixture $3 A+4 B$ will present exactly the same appearance as the mixture $2 C+6 D$. This is only another way of saying that colour as seen by nornal vision contains three independent variables, or requires three numbers for its specification. Any three colours of the spectrum will serve as the three specifying elements; for example, if we employ $A, B$, and $C$ to specify $D$, the specification will be-

$$
D=\frac{1}{2} A+\frac{2}{3} B-\frac{1}{3} C \text {. }
$$

Here we have one coefficient (that of $C$ ) with the negative sign. The three primary colours are defined to be those which will always have positive coefficients when they are employed as the specifying elements. In plainer words, all other colours can be exactly imitated by mixtures of the primaries, whereas, in the above example, the colour $D$ cannot be imitated by a mixture of $A, B$, and $C$.

The points of the spectrum at which the three primary colours are found, will not necessarily be the points which most strongly excite the three elementary colour-sensations respectively. On the contrary, as a matter of fact, the two extreme sensations (called by Maxwell the red and the blue) are very feebly excited at the parts of the spectrum where they are purest, namely, at the extreme ends of the spectrum; and the middle sensation, which is largely adulterated with the other two even at the point where it is purest (namely, at a point in the olive green, which is, accordingly, one of the three primaries), has not a maximum of intensity at this point, but increases in intensity as the brightest part of the spectrum is approached, and attains its maximum (for the solar spectrum obtained with a flint glass prism), somewhere between the fixed lines $E$ and $D$. The determination of the position of the middle primary in the spectrum, was made with considerable precision in the paper referred to ; but the faintness of the two extremities of the spectrum rendered wide slits necessary in examining these regions, and thus introduced inaccuracy in determining the positions of the two extreme primaries, which in later publications Prof. Maxwell places at the very extremities of the spectrum.

The latter part of the paper of 1860 consists of a postscript containing observations made by a colour-blind person. The colour-equations found by direct observation are given, and are shown to agree with the supposition that the observer's vision was dichroic, the sensation corresponding to the extreme red being absent. The curves of intensity for each of the two elements in the vision of the dichroic observer are given, side by side with the three curves of intensity for the vision of a trichroic observer, all these being directly calculated from the observations, and the two dichroic curves appear to be practically identical with two of the three trichroic curves.

Dr. Pole's objection to the received theory appears to me to have no force except in so far as it is an objection to a name. The colour which the colour-blind see in the less refrangible half of the spectrum appears to be due to the excitement of the middle one of the three elementary sensations of trichroic vision. Persons of normal vision never get this sensation without large adulteration, and bence ordinary language contains no appropriate name for it.

Prof. Hering's theory of colours, as expounded by Dr. Pole (NATURE, vol. xx. pp. 479,480 ) seems inconsistent with the fact (established by the observations of Prof. Maxwell, Lord Rayleigh, and other competent observers) that there is one definite colour-equation between any four colours. For Prof. Hering's theory assumes four elements of colour-sensation, $R, G, B, Y$, such that

$$
R+G=0, B+Y=0 \text {. }
$$

It would follow that, with the belp of the minus sign, alf colours could be specified in terms of $R$ and $B$, and hence by writing down the specifications of any three colours, and employing the ordinary processes of elimination, a colourequation could be obtained between the three colours. Prof. Hering's theory then leads to the result that there is a definite colour-equation between any three colours; in other words, that when any three colours are given it is possible to imitate one by a mixture of the other two. This result is so utterly opposed to fact, that a theory which leads to it cannot stand for a moment.

\section{J. D. EvERETT}

\section{SOME OBSERVATIONS ON FLEUSS'S NEW PROCESS OF DIVING AND REMAINING} UNDER WATER

I HAVE recently had two opportunities of seeing a new process of diving and of remaining for a long time under water, called, after its inventor, Fleuss's process. The peculiarity of it is that the diver takes down with him such a good and wholesome supply of air-food, that he is 